\title{
Environmental Engineering Research in September 2010
}

This issue is the first copy of the Environmental Engineering Research journal produced by the new editorial board, which was invited by the new president of Korean Society of Environmental Engineering when Jae-Woo began his term for 2010-2012. I, Dongil Seo of Chungnam Naitonal University, was appointed as a new editor in chief. Prof. Jaewoo Park in Hanyang University (Solid Waste, Groundwater), Prof Jihyang Kweon of Kunkook University (Water Quality, Ecology) and Chul-un Ro of Inha University (Air Quality, Health Issues), Korea agreed to serve as associate editors. The Previous editing board, led by Prof In S. Kim of Gwangju Institute of Science and Technology, did a great job preparing to register EER as a Scientific Citation Index journal. We expect EER to be registered as an SCI journal by early 2011. The editorial boards of EER were strengthened in 2010 with the invitation of 40 world class level experts from 14 different countries who have been active in various environmental engineering fields.

This issue of EER includes eight papers selected by our editorial boards. These papers can be grouped into three categories - optimization or modeling applications, experimental studies, and water quality analysis. Optimization or effect analysis papers include 1) application of the Taguchi optimization approach, which shows $96.7 \%$ improved methyl ester or biodiesel yield from rapeseed, 2) development of a more efficient water demand prediction model by cluster analysis and multiple regression method, and 3) modeling the effect of low impact development in the reduction of runoff and pollutant loads. Experimental studies papers include 4) microbial removal using layered double hydroxides (LDHs) and iron (hydr)oxides (IHs) immobilized onto granular media, 5) inhibition of inorganic nitrogen to methane oxidation, and 6) biofouling of Bacillus biofilm on reverse osmosis membranes. Water quality analysis papers include 7 ) the effect of land treatment as a tertiary treatment method of pulp and paper mill wastewater, and 8) water quality analysis of the Pasig river in Manila.

Readers are invited to enjoy online copies of EER dating back to 1996. Authors are encouraged to submit papers through our online manuscript submission, review, and tracking system. The editorial board will do our best to complete manuscript reviews within the specified time, or faster, with a high level of feedback.
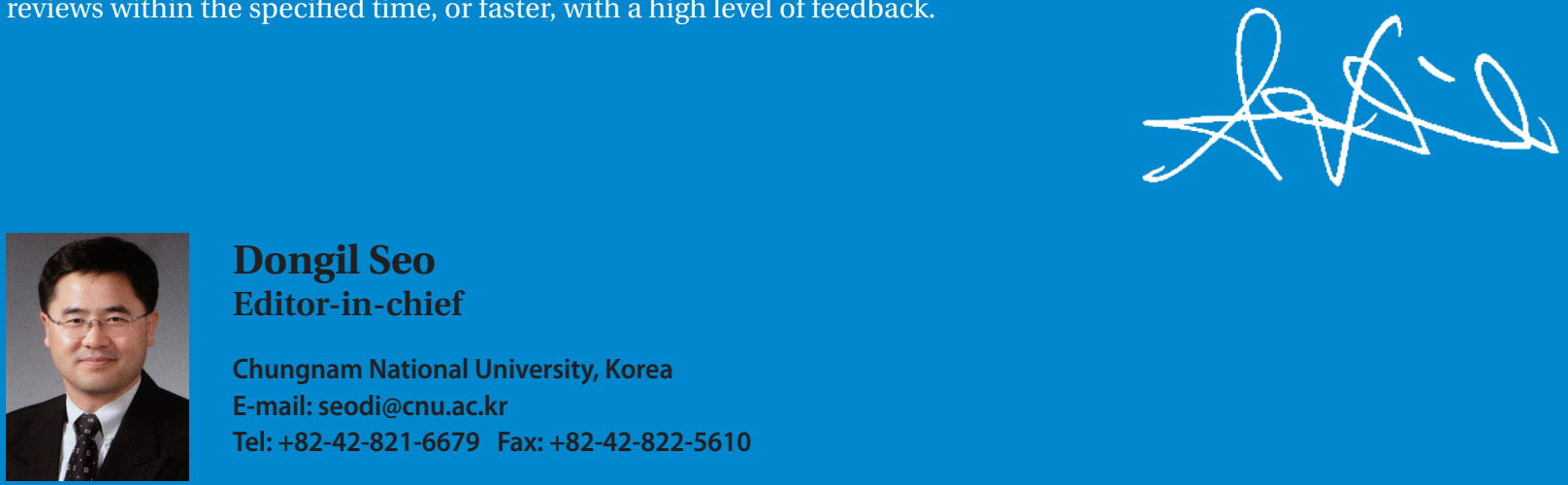

\section{Dongil Seo}

Editor-in-chief

Chungnam National University, Korea

E-mail: seodi@cnu.ac.kr

Tel: +82-42-821-6679 Fax: $+82-42-822-5610$ 